\section{"IS INSTRUMENTAL DELIVERY A CAUSE OF IDIOCY."}

\section{To the Editors of THE LANCET.}

SIRS,--My attention has been called to a paper by Drs. Winkler and Bollaan on the Forceps as a Cause of Idiocy. The importance which it has received by a reference to it in your columns leads me to call the attention of the profes sion to what I wrote in a paper entitled the "Obstetrical Aspects of Idiocy," published in the Obstetrical Society's Transactions, 1876. "I find, from an examination of all my cases of idiocy about which positive information could be obtained, that in only 3 per cent. were the forceps employed. In every case, however, where they had been employed, the friends of the child believed that the instrument alone was the cause of the disaster, while in nearly every case I could discover quite sufficient to account for the mental defect in the neurotic history of the progenitors. In a very few cases, only a small fractional percentage, could I arrive at the conclusion that the use of the forceps was the principal cause of the calamity. I find in a very large number of my cases that the labour was stated to be unusually tedious and prolonged. Dr. Playfair has shown that the employment of the forceps does not interfere with the viability of the offspring; and that a prolonged labour is more compromising to the life prospects of the child than a judicious and timely application of the forceps. "When it is borne in mind how frequent is the association of suspended animation with idiocy, it cannot, I think, be too strongly enforced that the mental integrity of the child is more likely to be comprimised by a prolonged pressure in the maternal passages than by skilled employment of artificial assistance. The accoucheur who postpones instrumental help often does so at the risk of terrible consequences to the nervous system of the little one he is solicitous to protect." In niy somewhat recent Lettsomian lectures delivered before the Medical Society of London I was able to confirm by additional experience that which I had so strongly enforced before. I am convinced that injury is likely to result from a reception of Drs. Winkler and Bollaan's teaching. I am, Sirs, yours faithfully,

Harley-street, W., Jan. 12th, 1889.

J. LANGDON DOWN.

\section{"ALBUMINURIA IN PHTHISIS AND ALPINE WINTER CLIMATES." \\ To the Editors of THE LANCET.}

SIRS,-On my return from a Cliristmas visit to the Grisons, I found in The LANCET of Jan. 5th, 1889, an interesting communication from Sir Andrew Clark entitled "The Peril incurred in Alpine Winter Climates of Renal Complications in Phthisis," in which complimentary allusion is made to my paper on "The Treatment of Consumption by Residence at High Altitudes," published in vol. lxxi. of the Medico-Chirurgical Transactions. I am very glad to have from Sir Andrew Clark's large experience such important confirmation of most of my conclusions, and I much reoret that he was prevented from being present at the discussion which followed the reading of the paper. Sir Andrew Clark draws attention to "a remarkable and inexplicable omission in both paper and discussion "-viz., that no notice is taken of the peril of sending cases of phthisis complicated with albuminuria to high altitudes. My answer to this is simple. I have never counselled sending snch patients to high altitudes; and whenever I have been consulted in such cases, have done my best to deter them from going; but to warn medical men against what appeared to me obvious-viz, the inadvisability of sending these cases-has hitherto seemed to me unnecessary. Now, when does albuminuria intervene in phthisis? Generally within a few months or weeks of the patient's death, except in the fibroid form, when it may appear earlier. It surely would be a doubtful proceeding to send to a high altitude Alpine station an advanced case of phthisis, with a necessarily small area of breathing space, and in whon the intropulsive action of a cold climate would tend to produce congestion of internal organs, including the kidneys. In the fibroid variety of phthisis, especially if the amount of induration is large, as Sir Andrew Clark says truly, albumen does sooner or later make its appearance ; but this is a class of cases which I exclude in my paper under the heading of "Cases of Phthisis where the Pulmonary Area at Low Levels hardly suffices for Respiratory Purposes." This does not apply to all cases of phthisis where fibrosis is present, but only where the changes so well described by Sir Andrew Clark are the chief feature. Therefore, while cordially endorsing the proposition that no cases of phthisis and albuminuria should ever be sent to high altitudes, I have thought this too self-evident to require formulation. I wish any readers of THE LANCET who may be sceptical as to the benefits of the high altitude treatment of phthisis could witness, as I did recently at Davos and St. Moritz, the weather-tanned consumptives pursuing their vigorous and enjoyable life in the clear buoyant diathermic climate, free from fog and wind, and rejoicing in sunshine and brightness. Owing to the early and comparatively small amount of snowfall, the lakes of Davos, St. Moritz, Silvaplana, and Sils formed splendid sheets of dark ice free from snow, and capital for skating and picnics. The recent fall of snow has ended most of the lake skating, but the rinks and toboggan runs are in full swing. The weather has been magnificent for sleighing excursions, and the whole outdoor life at high altitudes has been carried out under exceptionally favourable conditions, and I was pleased to find that the patients had improved accordingly.

If any of your readers should desire a copy of the abovementioned paper, which gives the results of this treatment in 141 cases of consumption, I shall have great pleasure in forwarding it to them.

I am, Sirs, faithfully yours,

C. Theodore Williams, M.A., M.D., F.R.C.P. January, 1889.

\section{"MEASLES AND ELEMENTARY SCHOOL CLOSURE:"}

To the Editors of THE LANCET.

SIRs, - I note in a recent issue of THE LANCET these words: "It is very desirable that the matter [closure of schools for measles] should be carefully studied." Will you allow me to add, the closure of schools for any epidemic disease? I send you some information on the subject, gained by myself as a member of a School Board having under its control eighteen blocks of school buildings, with an average attendance of 7800 children, for publication if you consider it of any value. It is important to note that in Burton the notification of infectious disease is compulsory, and that of the two diseases with which elementary schools are most concerned-scarlet fever and nueaslesthe former is scheduled and the latter is not.

Scarlet fever.-By the courtesy of the sanitary authority, the clerk to the School Board obtains returns of the cases notified, and sends a list of all such cases as may affect the elementary schools to the various head teachers. As a result of this arrangement, the Board becomes aware of the existence of an epidemic of scarlet fever before it has time to influence the school attendance, and is enabled to take measures to prevent the spread of the disease, such as the exclusion of all children from infected houses and the regulation of the return of convalescent children.

Schools not closed for scarlet fever. - It has been the practice of our Board, with the concurrence of my colleague, Dr. W. G. Lowe, and myself, not to close schools during an epidemic of scarlet fever, believing that to close the school where the first cases appear simply has the effect of spreading the epidemic throughout the district. And, as a matter of fact, two epidemics which have occurred in the school district during the past five years have practically been confined, in each instance, to a small portion of the town, and have at the most aftected only two blocks of schools.

In measles schools closed early.-Experience has taught us that, in dealing with measles, the sooner we close a school or schools where the disease is rife (and here note that we have no means of knowing of the existence of measles until it affects the school attendance), the sooner the disease is stamped out, and the less the school attendance, in the long run, suffers.

Effect of closing for a month. - The following figures will give some idea of the effect of closing schools on account of the existence of measles. A block of schools with accommodation for 1000 scholars had its average attendance reduced to about 75 per cent., and was closed for a month. The schools opened at the end of that time with an attendance of 88 per cent. in the boys and girls' department, and 68 in 